\title{
The Role of Sphenobasilar Synchondrosis in Disease and Health
}

Torsten Liem, MSc Ost, MSc Paed, DO (Germany)

Financial Disclosures: None

reported.

Support: None reported.

Address correspondence to

Torsten LieMSc Ost, MSc

Paed Ost, Osteopathie Schule Deutschland Mexikoring 19, 22297 Hamburg, Germany.

Email: tliem@osteopathie-

schule.de

Submitted

July 11, 2018;

revision received

May 13, 2019;

accepted

June 24, 2019.

Background: The sphenobasilar synchondrosis (SBS; also, sphenobasilar synostosis or sphenooccipital synchondrosis) plays a major role in the concept of osteopathic cranial manipulative medicine (OCMM) and craniosacral therapy. Previous research suggests that many individuals, from newborns to adults, present with single or multiple SBS strain patterns as a result of the birth process and other traumatic forces throughout life. To date, it is unclear whether specific SBS lesion patterns are present in altered health states and disease and how they compare with healthy controls.

Objective: To identify research that reports on specific SBS strain patterns compared with healthy controls.

Methods: A literature review of electronic databases and hand-search of publication bibliographies was performed. Observational studies of newborns, children, and adults were included if there was information on the occurrence of cranial strain patterns related to the SBS in individuals with impaired health states and a healthy control group.

Results: Of 1123 citations, 836 articles were screened after duplicate removal, and 42 articles were evaluated by full-text assessment. Three articles were included in this review, including 1 prospective and 2 retrospective studies. The age ranges of the populations studied were newborns aged 5 days or younger, children aged 4 to 14 years, and adults aged 45 to 90 years. In adults with Parkinson disease, no significant difference in SBS strain patterns between the Parkinson disease group and the age-matched healthy control group were seen. In contrast, different SBS strain patterns were observed between newborns with a range of health impairments, such as jaundice and respiratory and nervous symptoms, and children with learning disabilities compared with their healthy counterparts. However, no statistical analysis was conducted in these 2 studies; hence, results are difficult to interpret. Reporting in all 3 studies was limited; therefore, the methodologic quality of the 3 identified studies was deemed incapable of being judged.

Conclusion: The study landscape of this review highlights the scarcity of, poor reporting on, and unclear methodologic quality of research on SBS strain patterns in disease and health. It is still unclear whether and to what extent specific SBS strain patterns occur in impaired health states compared with healthy controls. Future studies should seek to improve study methods and reporting and minimize the risk of bias.

J Am Osteopath Assoc. 2020;120(6):404-412

doi:10.7556/jaoa.2020.062

Keywords: osteopathic cranial manipulative medicine, sphenobasilar synchondrosis, strain patterns 
$\mathrm{T}$ he sphenobasilar synchondrosis (SBS; also, sphenobasilar synostosis or sphenooccipital synchondrosis), representing the articulation between the occiput and the sphenoid bone, is regarded as a major component of the cranial model originated by William Garner Sutherland, DO, through his observations that the individual bones of the skull show mobility. ${ }^{1}$ According to Sutherland, movement or an autonomous event can affect the SBS, which in turn may have an impact on the reciprocal tension membranes and sutures of the skull. ${ }^{1}$ Harold Yves Magoun, DO, described the SBS as the “....key to understanding the entire cranium," and said, "Lesions of this mechanism can be profoundly significant." (pp 117) According to Magoun, the SBS relates to some of the most vital parts of the nervous system, and SBS strains are reportedly found by practitioners in patients with headache, facial paralysis, salivation, myopic astigmatism, vertigo, hypertension, sinusitis, and many other conditions. $^{2(\mathrm{p} 120)}$ Possible wider-ranging effects of these lesions may be an alteration of the vascular supply to vital areas of the central nervous system and the normal movement of the cerebrospinal fluid in the subarachnoid space. ${ }^{2(p p ~ 117-121)}$

The importance of the SBS in the current osteopathic literature is highlighted by these teachings, where strains of the SBS are thought to have an impact on health, or where the SBS should be assessed in patients with any complaint referring to the head, ears, nose, throat, and eyes. ${ }^{3,4}$

According to Richard Starkey, the term sphenobasilar synchondrosis is still used in much of the recent craniosacral literature without giving reference to the ossification status of the joint. ${ }^{5}$ He suggests that, in accordance with other authors, ${ }^{5,6}$ until the ossification of cartilaginous joints is complete, the SBS is referred to a synchondrosis, and once complete, it becomes a synostosis.

Cranial strain patterns that result from membranous articular strains due to abnormal dural membrane tensions ${ }^{7}$ are commonly presented by a free, prompt, and full motion of the occiput and sphenoid in a single direction at the SBS. ${ }^{8}$ Cranial strain patterns are classified as follows ${ }^{9-11}$ :

- Lateral (left or right)-occurs when the sphenoid and occiput rotate in the same direction about their respective vertical axis, creating a shear mode of motion in the SBS

- Sidebending/rotation (left or right)-occurs when the sphenoid and occipital arches rotate in opposite directions about 2 parallel vertical axes, 1 through the body of the sphenoid and the other through the foramen magnum

- Torsion (left or right)-occurs around an anteriorposterior axis of the skull as the sphenoid and occiput rotate in opposite directions

- Vertical (superior or inferior)-occurs when the sphenoid and occipital rotation is in the same direction about their respective transverse axes

- Compression-occurs when the sphenoid and occiput have been forced together so that physiologic flexion or extension is impaired

- Flexion-characterized by an elevated SBS, with an increased upward convexity

- Extension-when the SBS is lowered, the upward convexity is decreased

Some cranial strain patterns, particularly torsion and sidebending/rotation, are considered physiologic, such as those due to daily strains on the human body. ${ }^{10}$ Examples of common conditions reported to occur with these strain patterns are headache, endocrine disorders, motor disturbances, and other musculoskeletal conditions. ${ }^{12}$ Nonphysiologic strain patterns, such as vertical or lateral strain, usually are the result of major trauma, such as birth, surgical procedures, or external force. $^{8,12}$

While high-quality evidence is lacking, it is commonly speculated that osteopathic cranial manipulative medicine (OCMM) may be able to reduce cranial strains and restore normal mobility at the SBS and related structures, which would result in improved flow 
of blood and cerebrospinal fluid, hence, increased overall health of the patient. $^{2(p 117-121)}$

However, some authors have recently questioned the clinical significance of primary SBS lesion patterns and their treatment in adults, when considering the age of SBS ossification. According to recent research literature, ossification of the SBS is completed between ages 13 and 17 years. $^{13,14}$ In a previous study, $\mathrm{I}^{15}$ argued that once the SBS becomes ossified in early adulthood, the therapeutic relevance of the SBS region may become reduced. Starkey, ${ }^{5}$ in his review of arguments for or against movement at the SBS, concluded that due to ossification during early adulthood and subsequent lack of movement, subsequent SBS lesions could neither develop nor be removed by treatment.

Previous research suggested that a significant number of individuals, from newborns to adults, present with single or multiple cranial strain patterns as a result of the birth process and may encounter other traumatic forces throughout life. ${ }^{16-18}$

To understand the role of the SBS and its accompanying lesions in the process of health and disease in adults as well as children, a step forward may be to understand the occurrence of SBS strain patterns in both healthy and impaired states. To date, however, it is unclear whether specific SBS lesion patterns are present in altered health states and disease and how they compare with those present in healthy controls. This literature review aimed to identify research reporting on specific SBS strain patterns in patients with altered health states and disease compared with healthy controls, as part of prospective or retrospective observational studies.

\section{Methods}

A narrative literature review was performed by searching the following electronic databases from inception to May 13, 2018: PubMed, Physiotherapy Evidence Database, Osteopathic Medicine Digital Repository, Cochrane (all databases), Index to Chiropractic Literature, and The Journal of the American
Osteopathic Association. Additionally, Google Scholar was manually searched, and citation tracking was applied to all selected articles. The keywords sphenobasilar synchondrosis, sphenobasilar synostosis, sphenooccipital synchondrosis, spheno-occipitalsynostosis, and craniosacral were used to identify potentially suitable articles and studies. An additional search in all databases described above was performed on October 9, 2018, for the keyword cranial strain pattern. Observational studies of newborns, children, and adults were included if they presented information on the occurrence of cranial strain patterns related to the SBS in patients with impaired health states and also included a healthy control group.

Eligible information from original studies was narratively synthesized, including study design, objective, and study outcome concerning SBS strain patterns.

\section{Results}

Database searches revealed a total of 678 citations from the initial search and 445 citations from the updated search. After duplicate removal, 836 records were screened (Table 1). Of 42 articles evaluated by full-text assessment, 3 articles were selected for this review, including 1 prospective and 2 retrospective studies.

The study by Frymann ${ }^{19}$ examined 1250 newborns for anatomical disorders of the craniosacral system in relation to their symptoms.

Newborns aged 5 days or younger were included in this study if a history of labor was available. Each newborn included in the study was examined by a physician in the first 5 days after birth. Behavior and symptoms were categorized as asymptomatic (no abnormal symptoms noted), nervous (newborns with vomiting, loss of appetite, and failure to thrive; muscular hypertension, spasm, tremor; and insomnia), respiratory or circulatory problems (difficulty breathing or excessive mucus, circulatory stasis with cyanosis), and jaundiced with Down syndrome (infants with jaundice or Down syndrome appearance). Examination included observation of the whole child: posture, muscle tone, 


\begin{tabular}{|c|c|c|}
\hline Source & $\begin{array}{l}\text { No. of studies } \\
\text { retrieved May } \\
13,2018\end{array}$ & $\begin{array}{l}\text { No. of studies } \\
\text { retrieved } \\
\text { October 9, } \\
2018\end{array}$ \\
\hline PubMed & 226 & 212 \\
\hline $\begin{array}{l}\text { Physiotherapy } \\
\text { Evidence } \\
\text { Database }\end{array}$ & 2 & 0 \\
\hline $\begin{array}{l}\text { Osteopathic } \\
\text { Medicine Digital } \\
\text { Repository }\end{array}$ & 276 & 158 \\
\hline Cochrane Library & 3 & 0 \\
\hline $\begin{array}{l}\text { Index to } \\
\text { Chiropractic } \\
\text { Literature }\end{array}$ & 49 & 7 \\
\hline$J A O A$ & 99 & 63 \\
\hline Google Scholar & 23 & 5 \\
\hline Total & 678 & 445 \\
\hline
\end{tabular}

Abbreviations: JAOA, Journal of the American Osteopathic Association; SBS, sphenobasilar synchondrosis.

nervous irritability, color, and shape. The examination of the craniosacral system included the sacrum and skull, which included assessment of the condylar parts of the occiput, mobility of the SBS, and flexion and extension patterns, as well as vertical strain patterns and motility of the temporal bones. ${ }^{19}$

Of 1250 infants, 874 were classified as asymptomatic, 8 infants belonged to the group of jaundiced infants with Down syndrome, 157 had respiratory and circulatory problems, and 211 were classified as nervous.

In nervous infants, the incidence of SBS flexion strain patterns was highest (21\%) compared with all other classifications (7\% of infants with respiratory and circulatory problems, $8 \%$ asymptomatic infants, $14 \%$ of jaundiced infants with Down syndrome). ${ }^{19}$ Compression patterns were found in $36 \%$ of nervous infants, compared with $28 \%$ of jaundiced infants with Down syndrome, $19 \%$ of newborns with respiratory and circulatory issues, and $13 \%$ of asymptomatic newborns. The incidence of SBS torsional stress patterns was highest in newborns with respiratory and circulatory symptoms (36\%) compared with asymptomatic infants (30\%) (Table 2). No statistical analysis was performed between the groups, and the author's conclusion of the study results was that strain patterns within the developmental part of the occiput were of significance in the development of nervous symptoms, which may be commonly accompanied by flexion strain of the SBS and an extension strain of the sacrum as well as a higher frequency of compression of the SBS. A relationship between a torsion strain of the SBS together with restriction in temporal mobility was suggested in infants with respiratory and circulatory symptoms.

Another study by Frymann ${ }^{20}$ investigated the influence of cranial somatic dysfunctions on childhood learning disabilities. This was a retrospective study, using cases from the author's practice. Patients were aged between 4 and 14 years and were divided into the following categories: group 1 consisted of 74 students with no visual or learning disabilities, group 2 included 32 students with visual impairment but no learning disabilities, and group 3 consisted of 103 children with learning disabilities. ${ }^{20}$

According to this study, $73 \%$ of children with learning disabilities had a major traumatic event during or before birth, such as labor of 12 hours or more or prolonged periods of ineffective labor resulting in cesarean delivery. In children without learning disabilities, birth trauma was present in only $28 \%$.

Of the 103 children with learning disabilities, $86 \%$ received a diagnosis of lateral strain, $46 \%$ had vertical strain, and $40 \%$ had compression of the SBS. Of the 106 children without learning disabilities, $71 \%$ had a diagnosis of lateral strain-38\% with vertical strain and $32 \%$ with compression of the SBS (Table 2). ${ }^{20}$

Based on these results, I concluded that the whole range of traumatic patterns may be found in children with learning disabilities, as well as in children without learning disabilities.

Rivera-Martine $\mathrm{z}^{21}$ conducted a retrospective study of patients with Parkinson disease (PD) to compare palpatory observations of cranial SBS strain patterns with 
Table 2.

Characteristics of SBS ${ }^{\text {a }}$ Strain Pattern Studies Included

\begin{tabular}{|c|c|c|c|c|c|c|c|}
\hline Study & Design & $\mathbf{N}$ & Population & Objectives & $\begin{array}{l}\text { Structures } \\
\text { assessed }\end{array}$ & SBS Results & Comments \\
\hline Frymann19 (1966) & $\begin{array}{l}\text { Observational/ } \\
\text { prospective }\end{array}$ & 1250 & $\begin{array}{l}\text { Newborns: } \\
\text { - A; } n=874 \\
\text { JDS; } n=8 \\
\text { - RC; } n=157 \\
\text { NS } ; n=211\end{array}$ & $\begin{array}{l}\text { To assess for } \\
\text { anatomical } \\
\text { disorders of } \\
\text { the } \\
\text { craniosacral } \\
\text { system in } \\
\text { relation to } \\
\text { their } \\
\text { symptoms }\end{array}$ & $\begin{array}{l}\text { Sacrum, skull } \\
\text { (condylar parts of } \\
\text { the occiput, the } \\
\text { motility of the SBS, } \\
\text { flexion and } \\
\text { extension patterns, } \\
\text { vertical strain } \\
\text { patterns, and } \\
\text { motility of the } \\
\text { temporal bones) }\end{array}$ & 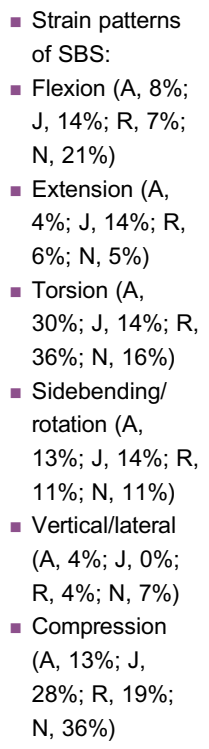 & $\begin{array}{l}\text { No statistical } \\
\text { analysis was } \\
\text { performed. The } \\
\text { most marked } \\
\text { difference between } \\
\text { A newborns and } \\
\text { those with } \\
\text { symptoms seemed } \\
\text { to be an increase } \\
\text { in SBS flexion and } \\
\text { compression } \\
\text { patterns in NS } \\
\text { newborns } \\
\text { compared with A } \\
\text { newborns ( } 8 \% \text { vs } \\
21 \% \text { and } 13 \% \text { vs } \\
36 \% \text {, respectively) }\end{array}$ \\
\hline Frymann20 (1976) & $\begin{array}{l}\text { Observational/ } \\
\text { retrospective }\end{array}$ & 209 & $\begin{array}{l}\text { Children aged 4-14 } \\
\text { years: } \\
\text { - With LDs }(n=103 \\
\text { - With NLD; } n=106\end{array}$ & $\begin{array}{l}\text { To investigate } \\
\text { the influence } \\
\text { of cranial } \\
\text { somatic } \\
\text { dysfunctions } \\
\text { on childhood } \\
\text { LDs }\end{array}$ & $\begin{array}{l}\text { Craniosacral } \\
\text { system (not further } \\
\text { defined) }\end{array}$ & 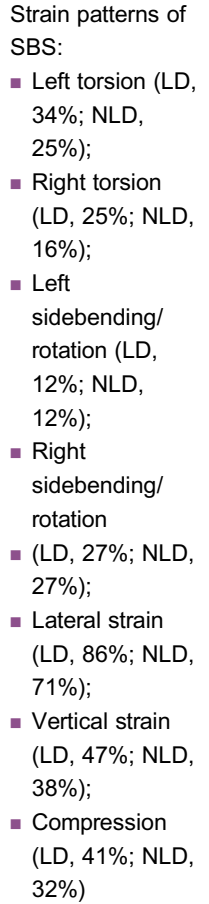 & $\begin{array}{l}\text { No statistical } \\
\text { analysis was } \\
\text { performed. The } \\
\text { most marked } \\
\text { difference between } \\
\text { children with LDs } \\
\text { and those with } \\
\text { NLDs seemed to } \\
\text { be an increase in } \\
\text { SBS torsion } \\
\text { patterns in children } \\
\text { with LDs }\end{array}$ \\
\hline
\end{tabular}


Table 2 (continued).

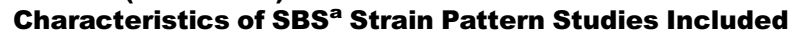

\begin{tabular}{|c|c|c|c|c|c|c|c|}
\hline Study & Design & $\mathbf{N}$ & Population & Objectives & $\begin{array}{l}\text { Structures } \\
\text { assessed }\end{array}$ & SBS Results & Comments \\
\hline $\begin{array}{l}\text { Rivera-Martinez21 } \\
\qquad(2002)\end{array}$ & $\begin{array}{l}\text { Observational/ } \\
\text { retrospective }\end{array}$ & 50 & $\begin{array}{l}\text { Adults: } \\
\text { With idiopathic } \\
\text { PD; } n=20 \\
\text { - Age-matched } \\
\text { HCs; } n=30\end{array}$ & $\begin{array}{l}\text { To compare } \\
\text { cranial } \\
\text { palpation } \\
\text { patterns in } \\
\text { patients with } \\
\text { PD with } \\
\text { cranial } \\
\text { palpation } \\
\text { findings from } \\
\text { HCs }\end{array}$ & $\begin{array}{l}\text { Strain patterns, } \\
\text { sutures or joint } \\
\text { restrictions, bony } \\
\text { motion restrictions }\end{array}$ & $\begin{array}{l}\text { Strain patterns of } \\
\text { SBS: } \\
\text { a Sidebending/ } \\
\text { rotation left (PD, } \\
\text { 7\%; C, 0\%) } \\
\text {. Sidebending/ } \\
\text { rotation right (PD, } \\
\text { 7\%; C, 10\%) } \\
\text { - Lateral strain left } \\
\text { (PD, 0\%; C, 5\%) } \\
\text { - Torsion left (PD, } \\
\text { 3\%; C, 5\%) } \\
\text {. Compression } \\
\text { (PD, 17\%; C, } \\
5 \%)\end{array}$ & $\begin{array}{l}\text { SBS compression } \\
\text { or other SBS } \\
\text { strains were } \\
\text { present in patients } \\
\text { with PD at a low } \\
\text { rate, which was not } \\
\text { statistically } \\
\text { different compared } \\
\text { with HCs }\end{array}$ \\
\hline
\end{tabular}

a In this review, sphenobasilar synchondrosis (SBS) includes spheno-occipital and sphenosynostosis.

b In this review, nervous symptoms (NSs) refer to vomiting, loss of appetite, and failure to thrive; muscular hypertension, spasm, tremor; and insomnia.

b In this review, respiratory or circulatory problems (RCs) refer to difficult breathing or excessive mucus, circulatory stasis with cyanosis).

Abbreviations: A, asymptomatic; HC, healthy control; JDS, jaundice with Down syndrome; LD, learning disability; NLD, no learning disability; PD, Parkinson disease; SBS, sphenobasilar synchondrosis.

common cranial palpation findings from healthy volunteers. $^{21}$

Thirty patients with idiopathic PD and 20 healthy controls of the same age were randomly identified from patient records of 3 osteopathic physicians. Records of patients and controls of both sexes were included in the study when patients were aged between 45 and 90 years regardless of ethnicity. Patients were excluded if there was evidence of head trauma in the past 2 months, a brain tumor, or a life-threatening illness. The primary data collected were evaluated by the respective osteopathic physicians or osteopathic manipulative medicine fellows under their supervision. ${ }^{21}$

The authors of this study found that patients with PD had a significantly higher incidence of bilateral atlantooccipital compression (87\%) and bilateral occipitomastoid compression (40\%) compared with healthy controls ( $50 \%$ and $10 \%$, respectively). There was no significant difference in SBS strain patterns between the groups (Table 2). ${ }^{21}$

\section{Discussion}

This literature review aimed to identify specific SBS strain patterns in impaired health states compared with healthy controls. Three studies, published in 1966, 1976, and 2003, were identified and included in this review. The age ranges of the populations studied in these publications were newborns, children, and adults.

In all 3 studies, the healthy controls all presented with low rates of SBS strain patterns, which were mostly physiologic. This finding has been described in the literature before and confirms current knowledge. ${ }^{16-18}$

In adults with PD, no significant difference in SBS strain patterns was noted when compared with the agematched healthy control group. ${ }^{21}$ However, some additional distinct articular restrictions and dysfunctions were seen in the patients with PD (bilateral atlantooccipital compression and bilateral occipitomastoid compression), which were significantly more present compared with the control group. Arguably, the sample sizes in both groups were small, which may 
have prevented a notable difference in SBS patterns between groups. Additionally, the severity of these SBS lesion patterns is unclear since this was not assessed. It could well be that SBS strain patterns were present at largely the same rates between both groups but that the severity may have differed, which may leave clues about a possible influence of these restrictions on the disease process. Starkey ${ }^{5}$ and $\mathrm{I}^{15}$ questioned the clinical significance of the SBS in adults as the primary lesion site, because of its ossified state. It appears that in the identified study of adults with PD, this argument might have merit, since no difference between SBS strain patterns was seen in the PD and control groups; however, it is unclear whether addressing these SBS strain patterns in the PD population would improve any of the symptoms or disease processes. Hence, the current evidence is to be interpreted with caution, and generalizability to other adult patient populations cannot be made. In infants and young children, the SBS is not yet ossified, and it could be speculated that specific SBS strain patterns may be prevalent in altered health states and that treatment of the SBS as the primary lesion site may be more relevant in this patient population.

The 2 identified studies by Frymann ${ }^{19,20}$ showed different SBS strain patterns between the affected groups of children with learning disabilities and newborns with a range of health impairment, compared with their healthy counterparts. However, no statistical analysis was performed in these studies, so the validity of these results is low and can serve as cause for speculation at best.

For applicability of these results, it is important to note the major study limitations. All 3 studies were published before the Strengthening the Reporting of Observational studies in Epidemiology (STROBE) guidelines came into effect in $2014 .^{22}$ Hence, reporting is limited and poor in the Frymann studies. ${ }^{19,20}$ Therefore, the methodologic quality of all 3 was deemed not capable of being judged. Future studies on SBS strain patterns should adhere to the STROBE reporting guidelines and take into account guidance on how to improve the methodologic quality of observational studies and minimize the risk of bias. ${ }^{23}$

Additionally, the risk of bias inherent to the assessment of SBS strain patterns cannot be underestimated. The physical assessment findings are subjective to each physician performing those assessments and are underlined by a variety of palpatory protocols that most likely differ between studies, so results should not be compared between studies, unless the same physicians perform these assessments. There may be the possibility of physician bias toward particular types of findings and methods of assessment. In all 3 studies in the current review, it is unclear whether the examiner who identified SBS strain patterns also took the case history of the patient and thus knew about the specific symptoms and problems of the patient, which I mentioned as an obstacle of cranial pattern palpation in my previous review. ${ }^{24}$ As previously described, habitual and context-related influences on palpatory outcomes could have affected the study results, such as pareidolia and cognitive bias as well as intuition or inattentional blindness. ${ }^{25}$ If a physician assesses strain patterns in both health-impaired and healthy individuals, it may be advantageous to blind the assessor to patient information to avoid those influences.

In terms of the number of physicians performing the assessment of the SBS strain patterns, it is unclear whether multiple assessors or single assessors would be more advantageous. Previous research suggests that there is substantial intrarater reliability when diagnosing cranial strain patterns. ${ }^{26}$ An interrater reliability study of cranial strain patterns and the cranial rhythmic impulse by Upldger $^{27}$ reported a match rate of $71 \%$ between 2 palpating osteopathic physicians. ${ }^{27}$ However, Upledger did not report the reliability of the assessment but provided the raw data from which an intraclass correlation coefficient was computed by Wirth-Patullo. ${ }^{28}$ The intraclass correlation coefficient was 0.57 (57\%), which was judged to be in the middle range and which Wirth-Patullo considered too low to support Upledger's conclusion that the investigation could be conducted with an acceptable level of 
reliability. ${ }^{28}$ Additionally, Hartman and Norton ${ }^{29}$ commented on the major weaknesses of the study methodology and implementation, as well as negligence in the measurement processes, which may have influenced the study results. ${ }^{29}$ Hence, interrater reliability in the assessment of cranial strain patterns remains unproven.

The present review has the following limitations. Only English language articles were included, which may have led to the exclusion of relevant articles in other languages. Authors of the original publications were not contacted for additional information on data. The search strategy for this narrative review was very specific with regard to the keywords used. Future reviews should include the keywords "osteopathy in the cranial field" and "osteopathic cranial manipulation" to broaden the search and increase the possibility of identifying additional publications on this topic. This research was performed by a single author; hence, potential publications may have been missed owing to a lack of confirmation by a second reviewer.

\section{Conclusion}

The identified study landscape of this review highlights scarcity, poor reporting, and unclear methodologic quality of research on the topic of SBS strain patterns in disease and health. Based on the findings of this review, it is unclear whether and to what extent specific SBS strain patterns in impaired health states compared with healthy controls occur. Future research should add to this limited evidence base, especially regarding assessment of SBS strain patterns, taking current research standards into account.

\section{References}

1. Sutherland WG. The Cranial Bowl. Free Press Company; 1939.

2. Magoun $\mathrm{HI}$, ed. Osteopathy in the Cranial Field. 3rd ed. Journal Printing Company; 1976.

3. Heinking KP, Kappler RE, Ramey KA. Head and suboccipital region. In: Chila A, ed. Foundations of Osteopathic Medicine. Lippincott Williams \& Wilkins; 2010:503.

4. King H. Osteopathy in the cranial field. In: Chila A, ed. Foundations of Osteopathic Medicine. Lippincott Williams \& Wilkins; 2010:737.
5. Starkey R. Arguments for and against movement at the spheno-occipital synostosis: furthering the debate. Int $\mathrm{J}$ Osteopath Med. 2015;18(2):102-115.

6. White TD, Black MT, Folkens PA. Human Osteology. Academic Press 2011:74,590.

7. Authorized Osteopathic thesaurus (AOT). American Association of Colleges of Osteopathic Medicine website. http://www.aacom.org/ news-and-events/publications/osteopathic-thesaurus. Accessed July 3 , 2018.

8. Sutherland WG. Membranous articular strains. In: Wales AL, ed. Teachings in the Science of Osteopathy. Sutherland Cranial Teaching Foundation Inc; 2003:156.

9. Magoun HI. Osteopathy in the Cranial Field. 3rd ed. Journal Printing Co; 1976:122-143.

10. Lay EM. Cranial field. In: Ward RC, ed. Foundations for Osteopathic Medicine. Baltimore, Md: William \& Wilkins; 1997:902-913.

11. Lippincott RC, Lippincott HA. A Manual of Cranial Technique. Cranial Academy; 1995:39-60, 119-123.

12. Upledger JE, Vredevoogd J. Dysfunctions of the cranial base. In: Craniosacral Therapy. Eastland Press; 1983:88-130.

13. Okamoto K, Ito J, Tokiguchi S, Furusawa T. High-resolution CT findings in the development of the sphenooccipital synchondrosis. AJNR. Am J Neuroradiol. 1996;17(1):117-120.

14. Bassed RB, Briggs $\mathrm{C}$, Drummer $\mathrm{OH}$. Analysis of time of closure of the spheno-occipital synchondrosis using computed tomography. Forensic Sci Int. 2010;200(1-3): 161-164. doi:10.1016/j. forsciint.2010.04.009

15. Liem T. Cranial Osteopathy: A Practical Textbook. Eastland Press; 2009.

16. Timoshkin EM, Sandhouse M. Retrospective study of cranial strain pattern prevalence in a healthy population. J Am Osteopath Assoc. 2008;108(11): 652-656.

17. Pizzolorusso G, Cerritelli F, D'Orazio M, et al. Osteopathic evaluation of somatic dysfunction and craniosacral strain pattern among preterm and term newborns. J Am Osteopath Assoc. 2013;113(6):462-467.

18. Waddington EL, Snider KT, Lockwood MD, Pazdernik VK. Incidence of somatic dysfunction in healthy newborns. J Am Osteopath Assoc. 2015;115(11):654-665. doi:10.7556/jaoa.2015.136

19. Frymann VM. Relation of disturbances of craniosacral mechanisms to symptomatology of the newborn: study of 1250 Infants. J Am Osteopath Assoc. 1966;65(10):1059-1075.

20. Frymann VM. Learning difficulties of children in the light of the osteopathic concept. J Am Osteopath Assoc. 1976;76(1):46-61.

21. Rivera-Martinez SONIA, Wells MR, Capobianco JD. A retrospective study of cranial strain patterns in patients with idiopathic Parkinson's disease. J Am Osteopath Assoc. 2002;102(8):417-422.

22. PLOS Medicine Editors. Observational studies: getting clear about transparency. PLoS Med. 2014;11(8):e1001711. doi: 10.1371/journal. pmed.1001711

23. Sanderson S, Tatt ID, Higgins J. Tools for assessing quality and susceptibility to bias in observational studies in epidemiology: a systematic review and annotated bibliography. Int J Epidemiol. 2007;36(3):666-676. doi:10.1093/ije/dym018 
24. Liem T. Review zur bedeutung der schädelbasis in der osteopathie. Osteopath Med. 2018;2:8-15.

25. Liem T. Pitfalls and challenges involved in the process of perception and interpretation of palpatory findings. Int J Osteopath Med. 2014;17 (4):243-249.

26. Halma KD, Degenhardt BF, Snider KT, Johnson JC, Flaim MS, Bradshaw D. Intraobserver reliability of cranial strain patterns as evaluated by osteopathic physicians: a pilot study. J Am Osteopath Assoc. 2008;108(9):493-502
27. Upledger JE. The reproducibility of craniosacral examination findings: a statistical analysis. J Am Osteopath Assoc. 1977;76(12):890-899.

28. Wirth-Patullo V, Hayes KW. Interrater reliability of craniosacral rate measurements and their relationship with subjects' and examiners' heart and respiratory rate measurements. Phys Ther 1994;74 (10):908-920. doi:10.1093/ptj/74.10.908

29. Hartman SE, Norton JM. Interexaminer reliability and cranial osteopathy. Sci Rev Altern Med. 2002;6:23-34.

(c) 2020 American Osteopathic Association

\section{Download JAOA PowerPoint Slides}

Readers can download Microsoft PowerPoint slides of figures published in The Journal of the American Osteopathic Association. When viewing the figure in the full text article on JAOA.org, simply click on the link "Slide (.ppt)." Copyright and citation information are automatically added to the slide for easy insertion into a PowerPoint presentation. 